A raíz del encargo bíblico, ganar el pan exige secarse la frente con un pañuelo de hilo. Una lástima. Para distinguirse, la gente y las instituciones necesitan afirmarse en algo fuera de serie. Hágame un mono exótico y pagará el colegio de los niños. También sobra un extra para la ropa Polo, es decir, para la dicha de tela.

Una gotita de perfume detrás de la oreja, ojalá huela a rosa de Bulgaria.

(Con lo que Pedro sana, Sancho adolece)

Ayuda memoria En estas improvisaciones, o cartas cruzadas, he oído los murmullos de Jean-Louis Houdebine, Mary Douglas y Erns Gombrich.

Manuel Corrada

Matemático graduado en la Facultad de Ciencias de la U. de Chile. Profesor en la Facultad de Matemáticas y en la Facultad de Arquitectura Diseño y Estudios Urbanos de la PUC. Ha sido profesor, investigador conferencista invitado en diversas universidades latinoamericanas europeas. Es autor de numerosos escritos sobre lógica, teoría de conjuntos y fundamentos de la matemática.

\section{Arquitectura Cotidiana} Albert Tidy

Hablar de arquitectura cotidiana como un segmento diferenciado dentro del quehacer arquitectónico resulta arriesgado puesto que inevitablemente involucra un juicio valórico respecto a la obra. El primer cuestionamiento surge desde la misma definición: ¿acaso existe aquella arquitectura que no tenga su origen en lo cotidiano?

La arquitectura como manifestación del hombre se origina como respuesta a la necesidad diaria del subsistir ante la adversidad del medio. Primero fue el concepto de refugio, originado en la caverna y en las primeras construcciones elementales, cuya finalidad era proporcionar cobijo y la protección, luego se multiplicó en aldeas y pueblos y junto con ello comenzaron las primeras civilizaciones. Nuevos programas surgieron con las nuevas necesidades tanto físicas como espirituales que demandaban las emergentes estructuras sociales para satisfacer los requerimientos del habitar y la convivencia en comunidad, hasta llegar a la ciudad contemporánea que hoy conocemos. Varios milenios han transcurrido desde entonces, y el campo de la arquitectura como disciplina se sitúa en una perspectiva relativamente reciente en la historia de la humanidad. El acto de habitar surge espontáneamente y prueba de ello son los innumerables ejemplos de arquitectura vernácula que subsisten hasta nuestros días, siendo fuente de inspiración y admiración de la rama culta del oficio.
Las variables que intervienen en la problemática arquitectónica hoy enfrentan un escenario naturalmente más complejo, abierto y sofisticado que evoluciona junto con el desarrollo de las sociedades y el progreso de la técnica; sin embargo, a pesar de la existencia de nuevas fronteras para la disciplina y la aparición de variables cada vez más complejas que intervienen en el habitar, las demandas inmediatas originadas en el cobijo y la protección permanecen prácticamente inalterables en el tiempo.

La obra de arquitectura está inevitablemente sometida al testeo de la experiencia cotidiana de usuario, quien establece juicios valóricos dimensionables sobre la base del grado de confort que la obra sea capaz de proporcionar, el arraigo emocional o el consenso estético de la aceptación. Sin pretender subestimar la importancia de la apreciación del destinatario, resultaría simplista medir el valor de una determinada obra de arquitectura desde esta perspectiva, ya que la popularidad en arquitectura no necesariamente es proporcional a la calidad de la propuesta. Lo mismo ocurre en el sentido inverso con obras emblemáticas cuyo aporte no siempre es valorado, llegando a instancias de franco rechazo por parte de la comunidad.

De este modo, la historia de la arquitectura se construye en base a selectos ejemplos que irrumpen como obras paradigmáticas de una determinada tendencia, movimiento o contexto específico. Lejos de ser un discurso estructurado y fluido, son sólo un puñado de obras las que llegan a coronarse como hitos representativos de un momento singular en la historia las que en forma aparente, nos proporcionan una síntesis de la arquitectura como totalidad. En consecuencia, la información disponible en el debate contingente y en la escena arquitectónica resulta naturalmente incompleta, puesto que depende directamente de la publicación como medio para su difusión, reconocimiento o condena.

Ante la imposibilidad de disponer de la información de todo aquello que teóricamente se circunscribe dentro del ámbito de la arquitectura, los medios de difusión surgen como mecanismo de selección cuyo objetivo es rescatar, promover y registrar aquella información para hacerla disponible a un universo más amplio que el de la experiencia espacial in situ.

"Yo publico, luego existo" parece ser una condición de nuestros tiempos para el oficio, que, lejos de ser condenable, es necesaria e indispensable; no obstante debe guardarse una distancia prudente en comprender la exposición como una herramienta de progreso y no como un fin de la disciplina. Rem Koolhas define al arquitecto contemporáneo como un ser sediento de reconocimiento que reacciona al más mínimo estímulo de la publicación como recompensa. En su discurso ofrecido el pasado año al recibir el premio Pritzker, nos ofrece una perspectiva poco optimista al comparar el rol del arquitecto hace 50 años como autoridad intelectual involucrada activamente en el progreso social, en contraposición con el rol individualista de la trascendencia personal motivada por el deseo de pertenecer al "star system" que los mismos medios de difusión han creado, reduciendo su labor como un bien transable que se ajusta a las reglas del mercado.

Sin embargo, aquella arquitectura que es reconocida no es un hecho aislado, sino más bien es la consecuencia de una reacción crítica a lo establecido que requiere de intentos fallidos y tiempo para su maduración. Son innumerables los casos de obras que han debido soportar el injusto rechazo de la indiferencia para más tarde gozar del rol protagónico que la historia les reservaría.

Sin pretender ser un acto de heroísmo forzado, el presente comentario tiene como fin reflexionar sobre los valores de aquella arquitectura que no forma parte del repertorio de obras trascendentes y que probablemente permanecerán radicadas en el olvido. Son obras que quizás injustamente hacen su aporte desde la discreción del anonimato y la sencillez de lo cotidiano, pero que indiscutiblemente forman parte de nuestra vida diaria y que en muchas ocasiones constituyen el punto de partida para nuevas ideas.

Lo enteramente original no existe en arquitectura. El poder visionario de maestros que han iluminado el camino de la arquitectura no ha sido fruto de la inspiración pura. Es el poder de observación de lo cotidiano y de lo circundante lo que afirma una visión crítica respecto a lo establecido para proponer una obra o pensamiento que se construye a lo largo del tiempo con el rigor de la perseverancia y el riesgo de la intuición.

"No soy un intelectual, soy un carpintero que conoce su oficio" afirma el otrora ebanista y diseñador suizo Peter Zumtor, quien, luego de una larga trayectoria como arquitecto y constructor, ha llegado a la cúspide de su carrera como arquitecto reconocido por la singularidad de su obra madura. Sin embargo, su obra no podría entenderse de otra manera que no sea la herencia de la tradición maderera de los Alpes ni el culto al rigor y la exactitud del pueblo Suizo. El agudo grado de observación y de edición de todo aquello que conforma el imaginario cotidiano, acerca la obra de este arquitecto a lo más profundo de la sensibilidad de los sentidos. El manejo de la luz 
sumado a las propiedades táctiles de los materiales y la belleza que inspira la tradición de la técnica dan forma a un lenguaje universal. El complejo termal en Vals, una de sus obras más celebradas, es una prueba de ello. Casi al finalizar el diseño del edificio el arquitecto visita los antiguos baños de Estambul, Budapest y Bursa y comenta: "En aquel momento comprendí no sólo de dónde proceden estas imágenes, sino que también forman parte de un legado universal y profundamente arcaico".

Es preocupante que con los avances de las comunicaciones sufrimos de una sobreexposición de información cada vez más lejana de nuestra realidad cotidiana. Con cierto temor he observado verdaderos cultos hacia tendencias que poco tienen que ver con nuestra realidad inmediata al ser extrapoladas de forma literal y que al cabo de un tiempo queda en evidencia su falta de sustancia al no resistir la prueba más dura de la permanencia. Quizás hace falta un acto de humildad para comprender que tras lo que aparentemente resulte poco atractivo e incluso desechable en una primera aproximación, probablemente pueda proporcionarnos las pistas para entender la labor del arquitecto como un fenómeno cultural único y valioso para cada contexto específico.

Albert Tidy

Arquitecto, Universidad de Chile (1992) y Master en Arquitectura, Universidad de Yale (1999). Trabaja entre 1993 y 1996 para Gonzalo Mardones, destacando su participación en los provectos Colegio Nido de Águilas, Showroom Duomo y el Plan General del Museo Interactivo Mirador. Actualmente se desempeña como profesor de Taller en la Universidad de Chile y en la Pontificia Universidad Católica de Chile, compatibilizando la docencia con el trabajo arquitectónico.

\section{La seducción de lo cotidiano}

\section{Mauricio Baros}

No se puede hablar de cotidianeidad sin antes tratar de definirla, o al menos enmarcarla dentro de un contexto. Términos como cotidianeidad, privacidad, colectividad, resultan a veces tan generales y particulares a la vez, que es imposible lograr una definición clara. Generales, porque nos entregan una noción totalmente abierta a todo; lo cotidiano es definido como "lo que ocurre diariamente", "lo usual", lo que es tremendamente vago, en cuanto la existencia es particular y personal a cada individuo lo que nos produce que el término de lo cotidiano se fragmente en miles de pequeñas cotidianeidades personales y particulares de cada uno. Lo que aquí nos interesa, sin embargo, es el lugar en donde ellas suelen encontrarse, en lo que denominamos lugares cotidianos. Lugares que deben su existencia al hecho de que entre los miles de cotidianos particulares que podemos tener, existe por lo menos un grupo de ellos que nos son comunes a un grupo mayor de personas, y estos grupos se encuentran fugazmente por momentos en espacios definidos y determinados para tal efecto. Es acerca de estos espacios de encuentro fugaz de los que queremos hablar aquí. Espacios como el café, la calle, el almacén de la esquina, etc. Lugares de los cuales han derivado muchos otros hoy en día; el café se transforma en cibercafé, la calle en galería comercial, el almacén en supermercado, etc. Hay un cambio de tiempo y de escalas significativo, la velocidad de la mirada del paso es otro, la escala crece considerablemente, pero en el fondo existen ciertos elementos invariantes en estos lugares cotidianos, que son los que queremos tratar a continuación.

... Los seres existen para los otros según el modo como se miran. $Y$ en ese mundo que estaba conociendo, existían varios modos que significaban ver: un mirar al otro sin verlo, un poseer al otro, un devorar al otro, y un apenas estar en el canto y que el otro esté alli también.

Ese estar en el canto es algo propio de lo cotidiano, el vivir en el intervalo entre dos situaciones, entre el espacio de la vida privada y la vida pública. Ese estar en el borde del algo posibilita esa mirada lateral, oblicua, tangencial a la gente y el espacio, puede ser una forma de estar y también de vivir Son intervalos, momentos y, por lo tanto, espacios, espacios laterales, de fuga, espacios de fuga de la mirada y de la propia presencia en el lugar. La silla del café junto a la ventana, la acera, los corredores de una universidad, una esquina. Esta tangencialidad nace de lo cotidiano y a la vez lo condiciona; en el momento que pierde esta lateralidad y pasa a ser punto focal es otra cosa. Lo cotidiano asíse caracteriza por esta situación de un "estar abierto", abierto a la mirada, a la fuga, es un momento en viaje.

Y por ser tan transitoria y fugaz, esta cotidianeidad está sujeta al tiempo, a la hora. Los usos de nuestros cotidianos son muy efímeros durante el día, es decir, podríamos decir, que hay cierto tiempo en cuanto horario para lo cotidiano. As como resulta ser un intervalo entre dos vidas, también es un intervalo entre dos tiempos, un momento robado a la rutina diaria y, por lo tanto, fugaz. Son los minutos robados a una existencia quizás demasiado medida, demasiado normada. Es un burto hecho al tiempo y al espacio, los espacios cotidianos vienen a ser los reductos en donde depositamos el botín de los minutos robados a nuestra propia rutina. $Y$ es un burto compartido, y una complicidad también compartida.

Lo cotidiano posee también como particularidad ese weathearing, ese uso que se hace de un lugar. Existe un compromiso, una cierta complicidad con los lugares cotidianos. Este uso, sin embargo, implica un desgaste. Es aquel roce lateral, aquella marca que dejan los cuerpos al rozarse con un objeto, al ocupar los espacios, cuerpos extranjeros. El cuerpo tiende a hacer suyo lo cotidiano, amoldándolo, y lo cotidiano por su parte tiende a envolver al cuerpo. Este amoldamiento de lo cotidiano no es sino una manera de hacer nuestro ese momento, ese lugar, una manera de poseer; de esta forma se genera una pertenencia extranjera, me pertenece algo que no es mío, y es eso lo que lo hace especial. Es algo personal, mío, pero a la vez de otra persona, privacidades compartidas. Hay una cierta complicidad tremendamente seductora en el uso de los espacios cotidianos.

Lo cotidiano, por su parte, envuelve al cuerpo con sus olores, sabores, etc. En él nosotros somos protagonistas, parte de esa seducción. Porque lo cotidiano implica la presencia y uso humano masivos. Lo cotidiano requiere del "contacto" del día a día, de esa fricción, ese roce diario.

Hay algo tremendamente seductor en lo cotidiano por lo breve de su existencia. Lo cotidiano vive una existencia breve pero intensa.

Esta transitoriedad de los espacios cotidianos obliga a una cierta levedad espacial, si lo pudiésemos así denominar. Levedad entendida como un velo, como una espacialidad fina que se teje sobre una realidad física. Son los usos cotidianos, la intensidad de sus vivencias las que tejen este velo fino sobre un espacio físico generalmente "común", sin atributos. Siendo su único atributo el tener la capacidad de sostener diariamente el velo de cotidianeidad que la cubre. De esta manera hemos visto algunos de los atributos de lo cotidiano, sin siquiera llegar a poder definirlo, porque así como uno de estos atributos es el de la mirada fugaz, también la definición nos resulta esquiva y se nos escapa entre los dedos. Tal vez sea lo propio de lo cotidiano el quedar en ese ámbito que es indefinido pero a la vez tremendamente familiar. ... Lo que tenía el gusto que la lengua tiene en la propia boca. $Y$ la ausencia de tal nombre es como la ausencia de nombre que la lengua tiene en la boca. No era, pues nada más que eso...

Las citas son del libro A Mą̧a no escuro de Clarice Lispector (Ed. Rocco Ltda., Rio de Janeiro, 1998).

Mauricio Baros

Arquitecto, Universidad de Chile (1986). Magister en Arquitectura Pontificia Universidad Católica de Chile (1993). Actualmente es docente de las universidades Católica, de Chile y Central. 